Article

\title{
Surface Chirality in Rotational Magnetoelectrodeposition of Copper Films
}

\author{
Iwao Mogi ${ }^{1, * \mathbb{C}}$, Ryoichi Morimoto ${ }^{2}$, Ryoichi Aogaki ${ }^{3}$ and Kohki Takahashi ${ }^{1}$ \\ 1 Institute for Materials Research, Tohoku University, Katahira, Aoba-ku, Sendai 980-8577, Japan \\ SAITEC, Kawaguchi, Saitama 333-0844, Japan \\ 3 Department of Product Design, Polytechnic University, Sumida-ku, Tokyo 130-0026, Japan \\ * Correspondence: mogi@imr.tohoku.ac.jp
}

Received: 19 August 2019; Accepted: 9 September 2019; Published: 12 September 2019

check for updates

\begin{abstract}
Chiral surface formation was investigated in rotational magnetoelectrodeposition (RMED) of copper films, where an electrochemical cell was rotated in magnetic fields. The RMED was conducted with clockwise or anticlockwise rotation in the magnetic fields parallel or antiparallel to the ionic currents. The rotational frequencies were $0.5-6 \mathrm{~Hz}$, and the magnetic fields were 2-5 T. The chiral behaviors are divided into four types: type I has chirality depending on the magnetic field polarity, type II has chirality depending on the rotational direction, and type III has chirality depending on both directions. Type IV represents chiral symmetry breaking, where the RMED films exhibit only $\mathrm{L}$ activity in any magnetic field polarity and rotational direction.
\end{abstract}

Keywords: magnetohydrodynamics; surface chirality; magnetoelectrodeposition; system rotation; alanine; micro-MHD vortex

\section{Introduction}

Chiral surfaces of solid materials could serve as a chiral catalyst, which plays an indispensable role in enantioselective processes of the pharmaceutical industry. An electrochemical study of chiral surface formation was reported on chiral electrodeposition of $\mathrm{CuO}$ by Switzer et al. [1]. Magnetoelectrodeposition (MED; electrodeposition under magnetic fields) has potential to produce chiral surfaces on metal films [2-7]. When a magnetic field is imposed perpendicularly to a working electrode surface, two types of magnetohydrodynamic (MHD) flows are excited around the electrode $[8,9]$. One is a macroscopic vertical MHD flow near the electrode edge, the other is micro-MHD vortices around local bumps on the deposit surface, as shown in Figure 1a. A lot of screw dislocations exist on the surfaces of copper electrodeposit films [10]. The micro-MHD vortices affect the formation of right- and left-handed screw dislocations, leading to the surface chirality [9].

In the micro-MHD effect, both clockwise and anticlockwise vortices must coexist on the electrode surface such that the adjoining flows never conflict with each other. Thus, the self-organized micro-MHD state is symmetric. Aogaki and Morimoto proposed two mechanisms to break the symmetry in the micro-MHD vortices [9]. The first one is the influence of vertical MHD flow on the micro-MHD vortices. When the micro-MHD vortices are excited under the vertical MHD flow, the cyclonic micro-MHD vortices would be stable, and the anti-cyclonic vortices would become unstable [11,12], resulting in the different relative amounts of right- and left-handed chiral sites on the deposit surfaces. Our previous paper reported the validity of this mechanism by means of the MED with a tube wall around the electrode, where the surface chirality disappeared with suppression of vertical MHD flows [13]. Another mechanism is a system rotation, which is the rotation of an electrolytic cell in magnetic fields. This is termed as rotational magnetoelectrodeposition (RMED) [14]. The system rotation causes the precession of micro-MHD vortices through the Coriolis force (Figure 1b), and induces asymmetric 
effects on the clockwise and anticlockwise vortices, leading to the surface chirality. The surface chirality is expected to depend on the combination of magnetic field strength and rotational frequency, and thus RMED can be expected to lead to a novel technique to control the surface chirality of metal films. In this study, we have conducted RMED of $\mathrm{Cu}$ films with various magnetic fields and rotational frequencies, and examined the surface chirality of such RMED films. Here we show the unique chiral behaviors of RMED films.

$\mathbf{a}$

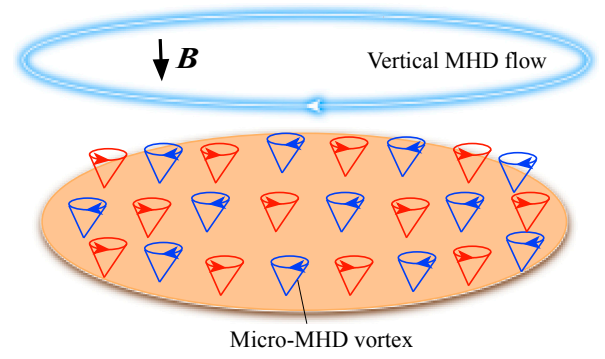

b

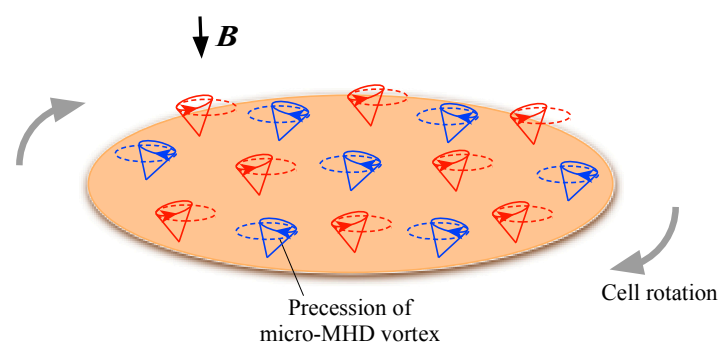

Figure 1. (a): Self-organized state of micro-magnetohydrodynamic (MHD) vortices under the vertical MHD flow. (b): Precession of micro-MHD vortices in rotational magnetoelectrodeposition (RMED) processes.

\section{Materials and Methods}

\subsection{Electrochemical Procedures}

In the electrochemical cell of RMED experiments, a conventional three-electrode system was employed: a polycrystalline $\mathrm{Cu}$ disc working electrode with a diameter of $3.2 \mathrm{~mm}$, a Cu plate counter electrode, and a $\mathrm{Cu}$ wire reference electrode. The $\mathrm{Cu}$ films were electrodeposited on the working electrode via the potentiostatic electrodeposition at a potential of $-0.45 \mathrm{~V}$ (vs. $\mathrm{Cu}$ ) in a $50 \mathrm{mM} \mathrm{CuSO}_{4}$ aqueous solution containing $0.5 \mathrm{M} \mathrm{H}_{2} \mathrm{SO}_{4}$. In order to reduce the influence of vertical MHD flows, the working electrode was embedded in a tube wall (Figure 2), and a pulse electrodeposition was conducted with a pulse width of $5 \mathrm{~s}$. The total passing charge was $0.4 \mathrm{C} \mathrm{cm}^{-2}$, and the film thickness was approximately $150 \mathrm{~nm}$.

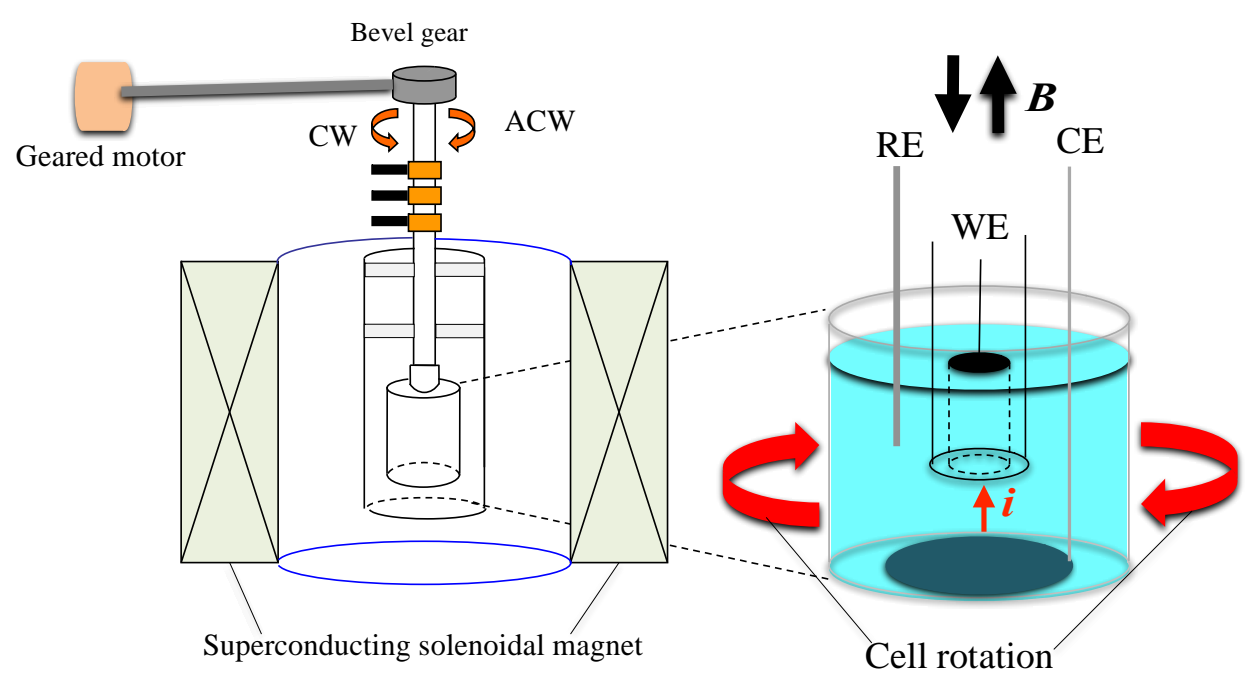

Figure 2. Schematic of RMED procedure. WE, a working electrode; CE, a counter electrode; and RE, a reference electrode. 


\subsection{RMED Procedures}

The RMED was conducted with a hand-made experimental system as shown in Figure 2. The electrochemical cell was placed at the center of cylindrical bore in a cryocooled superconducting solenoidal magnet (Sumitomo Heavy Industries Ltd. Tokyo, Japan), which can generate magnetic fields of up to $10 \mathrm{~T}$ (tesla). The imposed magnetic fields $B$ were perpendicular to the working electrode surface, and parallel (+) or antiparallel (-) to the ionic currents $i$ (Figure 2). The cell was rotated by a geared motor system with a bevel gear and a non-magnetic stainless-steel shaft. Because the geared motor was sensitive to stray magnetic fields, it was placed at a distance of $2 \mathrm{~m}$ from the magnet center, where the magnetic field was less than $5 \mathrm{mT}$. The rotational frequencies were $0.5-6 \mathrm{~Hz}$ with clockwise (CW) or anticlockwise (ACW) directions (viewed from the bottom of cell).

\subsection{Estimation of Surface Chirality}

To estimate the surface chirality of RMED films, the just-prepared films were used as electrodes after the pretreatment of a potential sweep from -0.3 to $0.3 \mathrm{~V}$ in a $0.1 \mathrm{M} \mathrm{NaOH}$ aqueous solution [3], and the voltammogram of $\mathrm{L}$ - or D-alanine was measured on such a film electrode. The voltammetric measurements were conducted in a $20 \mathrm{mM}$ L- or D-alanine $+0.1 \mathrm{M} \mathrm{NaOH}$ aqueous solution with a potential sweep rate of $10 \mathrm{mV} \mathrm{s}^{-1}$ in the absence of a magnetic field.

The chirality in voltammograms was evaluated by an enantiomeric excess (ee) ratio defined as

$$
e e=\left(i_{\mathrm{p}}^{\mathrm{L}}-i_{\mathrm{p}}{ }^{\mathrm{D}}\right) /\left(i_{\mathrm{p}}{ }^{\mathrm{L}}+i_{\mathrm{p}}^{\mathrm{D}}\right)
$$

where $i_{\mathrm{p}}{ }^{\mathrm{L}}$ and $i_{\mathrm{p}} \mathrm{D}$ represent the peak currents of $\mathrm{L}$ - and D-alanines, respectively. The positive sign of the $e e$ ratio represents L-activity, and the negative one represents D-activity. The ee ratios were obtained by one experiment at each condition, thus the errors are not reported. However, the RMED experiments were conducted more than 200 times in various magnetic fields and rotational frequencies to explore the systematic chiral behavior of the RMED films.

\section{Results and Discussion}

Figure 3 shows the voltammograms on $\{2 \mathrm{~T}, 4 \mathrm{~Hz}\}$ film electrodes, which represent the RMED films prepared at $2 \mathrm{~T}$ and $4 \mathrm{~Hz}$. The current increase around $0.6-0.7 \mathrm{~V}$ in all voltammograms corresponds to the oxidation currents of alanine molecule [15], and the current difference between L- and D-alanines represents chiral behavior. In Figure 3a, the currents of D-alanine are greater than those of L-alanine, thus the $\{+2 \mathrm{~T}, \mathrm{CW} 4 \mathrm{~Hz}\}$ film exhibits D-activity. Similarly, the $\{+2 \mathrm{~T}, \mathrm{ACW} 4 \mathrm{~Hz}\}$ film exhibits D-activity (Figure $3 \mathrm{~b}$ ). On the contrary, the films of $\{-2 \mathrm{~T}, \mathrm{CW} 4 \mathrm{~Hz}\}$ and $\{-2 \mathrm{~T}, \mathrm{ACW} 4 \mathrm{~Hz}\}$ exhibit L-activity (Figure $3 c, d)$. These results represent that the chiral signs of $\{2 \mathrm{~T}, 4 \mathrm{~Hz}\}$ films depend on the magnetic field polarity.

On the other hand, Figure 4 shows the results of $\{4 \mathrm{~T}, 2 \mathrm{~Hz}\}$ films, where the $\{+4 \mathrm{~T}, \mathrm{CW} 2 \mathrm{~Hz}\}$ and $\{-4 \mathrm{~T}, \mathrm{CW} 2 \mathrm{~Hz}\}$ films exhibit L-activity (Figure $4 \mathrm{a}, \mathrm{c}$ ), and the $\{+4 \mathrm{~T}, \mathrm{ACW} 2 \mathrm{~Hz}\}$ and $\{-4 \mathrm{~T}, \mathrm{ACW} 2 \mathrm{~Hz}\}$ films exhibit D-activity (Figure $4 \mathrm{~b}, \mathrm{~d}$ ). These results represent that the chiral sign of $\{4 \mathrm{~T}, 2 \mathrm{~Hz}\}$ films depend on the rotational direction. This means that the cell rotation allows control of the surface chirality. 

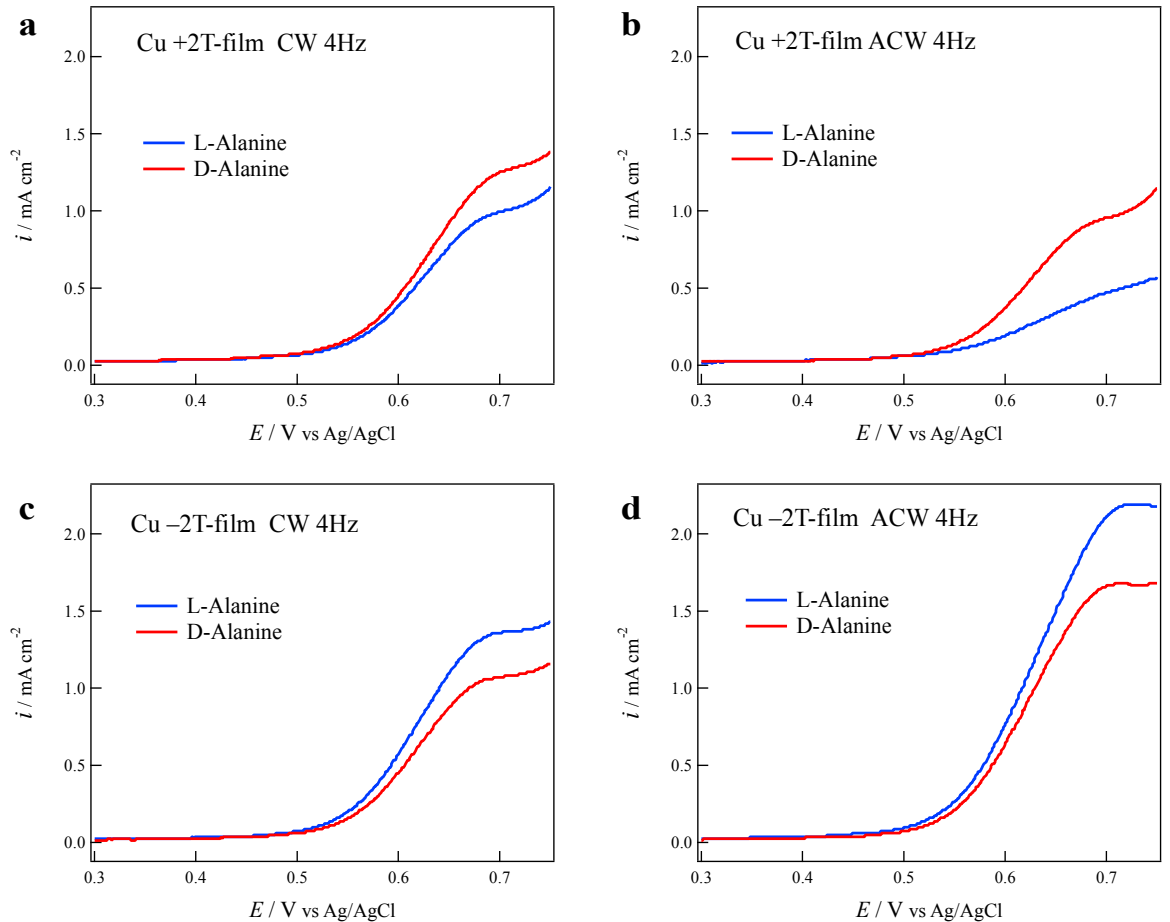

Figure 3. Voltammograms of alanine enantiomers on the RMED $\{2 \mathrm{~T}, 4 \mathrm{~Hz}\}$-film electrodes. (a): $\{+2 \mathrm{~T}$, CW $4 \mathrm{~Hz}\},(\mathbf{b}):\{+2 \mathrm{~T}, \mathrm{ACW} 4 \mathrm{~Hz}\},(\mathbf{c}):\{-2 \mathrm{~T}, \mathrm{CW} 4 \mathrm{~Hz}\}$ and (d): $\{-2 \mathrm{~T}, \mathrm{ACW} 4 \mathrm{~Hz}\}$.
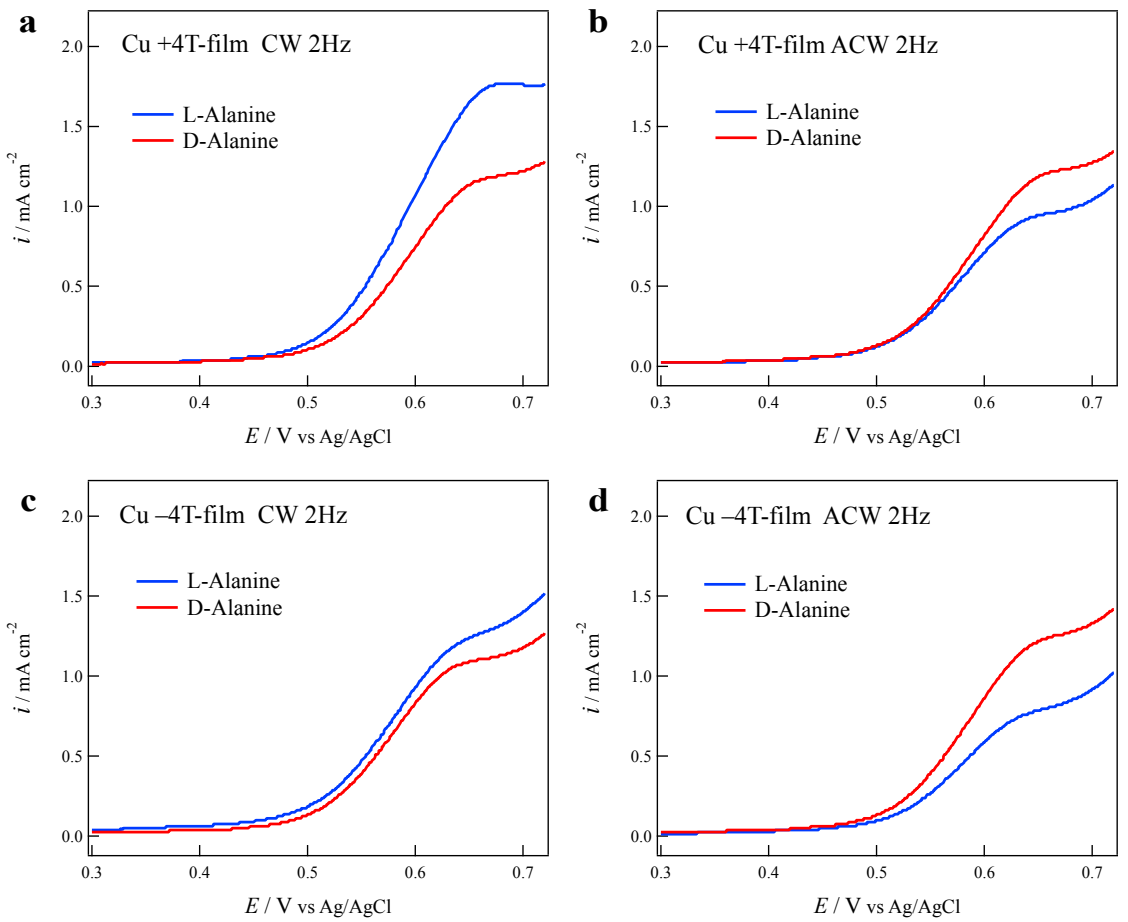

Figure 4. Voltammograms of alanine enantiomers on the RMED $\{4 \mathrm{~T}, 2 \mathrm{~Hz}\}$-film electrodes. (a): $\{+4 \mathrm{~T}$, CW $2 \mathrm{~Hz}\},(\mathbf{b}):\{+4 \mathrm{~T}, \mathrm{ACW} 2 \mathrm{~Hz}\},(\mathbf{c}):\{-4 \mathrm{~T}, \mathrm{CW} 2 \mathrm{~Hz}\}$ and (d): $\{-4 \mathrm{~T}, \mathrm{ACW} 2 \mathrm{~Hz}\}$.

Figure 5 shows the chiral behaviors of the RMED films prepared in various conditions of magnetic fields and rotational frequencies, where each table contains the chiral sign (L or D) and the ee ratios (in parenthesis) corresponding to the magnetic field polarities and the rotational directions. These tables are divided to four types I-IV. Type I exhibits the chiral signs depending on the magnetic field 
polarity, as shown in Figure 3. This indicates that the effect of vertical MHD flow is dominant in this type. The vertical MHD flow could make cyclonic micro-MHD vortices stable, and such stable micro-vortices contribute to the formation of chiral dislocations. The vertical MHD flow can be excited at the entrance of tube, then it could penetrate into the tube and arrive at the electrode surface [13]. The direction of vertical MHD flow depends on the magnetic field polarity, thus the chiral behavior of type I is responsible for the effect of vertical MHD flow.

Type I

\begin{tabular}{|c|c|c|}
\hline \multirow{2}{*}{$\boldsymbol{B} / \mathrm{T}$} & \multicolumn{2}{|c|}{ Rotation } \\
\cline { 2 - 3 } & $\mathrm{CW} 6 \mathrm{~Hz}$ & $\mathrm{ACW} 6 \mathrm{~Hz}$ \\
\hline$(+) 3$ & $\mathbf{D}(-0.069)$ & $\mathbf{D}(-0.067)$ \\
\hline$(-) 3$ & $\mathbf{L}(0.27)$ & $\mathbf{L}(0.20)$ \\
\hline
\end{tabular}

\begin{tabular}{|c|c|c|}
\hline \multirow{2}{*}{$\boldsymbol{B} / \mathrm{T}$} & \multicolumn{2}{|c|}{ Rotation } \\
\cline { 2 - 3 } & CW 6Hz & ACW 6Hz \\
\hline$(+) 2$ & D $(-0.25)$ & D $(-0.073)$ \\
\hline$(-) 2$ & $\mathbf{L}(0.26)$ & $\mathbf{L}(0.035)$ \\
\hline
\end{tabular}

\begin{tabular}{|c|c|c|}
\hline \multirow{2}{*}{$\boldsymbol{B} / \mathrm{T}$} & \multicolumn{2}{|c|}{ Rotation } \\
\cline { 2 - 3 } & CW 4Hz & ACW 4Hz \\
\hline$(+) 2$ & D (-0.12) & D $(-0.31)$ \\
\hline$(-) 2$ & L $(0.12)$ & L $(0.13)$ \\
\hline
\end{tabular}

\section{Type II}

\begin{tabular}{|c|c|c|}
\hline \multirow{2}{*}{$\boldsymbol{B} / \mathrm{T}$} & \multicolumn{2}{|c|}{ Rotation } \\
\cline { 2 - 3 }$(+) 4$ & CW $2 \mathrm{~Hz}$ & ACW $2 \mathrm{~Hz}$ \\
\hline$(-) 4$ & $\mathbf{L}(0.068)$ & $\mathbf{D}(-0.13)$ \\
\hline
\end{tabular}

Type III

\begin{tabular}{|c|c|c|}
\hline \multirow{2}{*}{$\boldsymbol{B} / \mathrm{T}$} & \multicolumn{2}{|c|}{ Rotation } \\
\cline { 2 - 3 } & $\mathrm{CW} 6 \mathrm{~Hz}$ & $\mathrm{ACW} 6 \mathrm{~Hz}$ \\
\hline$(+) 5$ & $\mathbf{L}(0.094)$ & $\mathbf{L}(0.12)$ \\
\hline$(-) 5$ & $\mathbf{D}(-0.28)$ & $\mathbf{L}(0.36)$ \\
\hline
\end{tabular}

\begin{tabular}{|c|c|c|}
\hline \multirow{2}{*}{$\boldsymbol{B} / \mathrm{T}$} & \multicolumn{2}{|c|}{ Rotation } \\
\cline { 2 - 3 } & CW 4Hz & ACW 4Hz \\
\hline$(+) 5$ & D $(-0.14)$ & $\mathbf{L}(0.32)$ \\
\hline$(-) 5$ & L $(0.041)$ & $\mathbf{L}(0.41)$ \\
\hline
\end{tabular}

\begin{tabular}{|c|c|c|}
\hline \multirow{2}{*}{$\boldsymbol{B} / \mathrm{T}$} & \multicolumn{2}{|c|}{ Rotation } \\
\cline { 2 - 3 } & $\mathrm{CW} 4 \mathrm{~Hz}$ & $\mathrm{ACW} 4 \mathrm{~Hz}$ \\
\hline$(+) 4$ & $\mathbf{D}(-0.051)$ & $\mathbf{L}(0.44)$ \\
\hline$(-) 4$ & $\mathbf{L}(0.31)$ & $\mathbf{L}(0.12)$ \\
\hline
\end{tabular}

\begin{tabular}{|c|c|c|}
\hline \multirow{2}{*}{$\boldsymbol{B} / \mathrm{T}$} & \multicolumn{2}{|c|}{ Rotation } \\
\cline { 2 - 3 } & $\mathrm{CW} 4 \mathrm{~Hz}$ & $\mathrm{ACW} 4 \mathrm{~Hz}$ \\
\hline$(+) 3$ & $\mathbf{L}(0.16)$ & $\mathbf{D}(-0.017)$ \\
\hline$(-) 3$ & $\mathbf{D}(-0.025)$ & $\mathbf{D}(-0.15)$ \\
\hline
\end{tabular}

\begin{tabular}{|c|c|c|}
\hline \multirow{2}{*}{$\boldsymbol{B} / \mathrm{T}$} & \multicolumn{2}{|c|}{ Rotation } \\
\cline { 2 - 3 } & $\mathrm{CW} 2 \mathrm{~Hz}$ & $\mathrm{ACW} 2 \mathrm{~Hz}$ \\
\hline$(+) 3$ & $\mathbf{D}(-0.26)$ & $\mathbf{L}(0.14)$ \\
\hline$(-) 3$ & $\mathbf{D}(-0.24)$ & $\mathbf{D}(-0.25)$ \\
\hline
\end{tabular}

\begin{tabular}{|c|c|c|}
\hline \multirow{2}{*}{$\boldsymbol{B} / \mathrm{T}$} & \multicolumn{2}{|c|}{ Rotation } \\
\cline { 2 - 3 } & $\mathrm{CW} 0.5 \mathrm{~Hz}$ & $\mathrm{ACW} 0.5 \mathrm{~Hz}$ \\
\hline$(+) 2$ & $\mathbf{L}(0.27)$ & $\mathbf{L}(0.13)$ \\
\hline$(-) 2$ & $\mathbf{D}(-0.58)$ & $\mathbf{L}(0.028)$ \\
\hline
\end{tabular}

Type IV

\begin{tabular}{|c|c|c|}
\hline \multirow{2}{*}{$\boldsymbol{B} / \mathrm{T}$} & \multicolumn{2}{|c|}{ Rotation } \\
\cline { 2 - 3 } & $\mathrm{CW} 2 \mathrm{~Hz}$ & $\mathrm{ACW} 2 \mathrm{~Hz}$ \\
\hline$(+) 5$ & $\mathbf{L}(0.46)$ & $\mathbf{L}(0.32)$ \\
\hline$(-) 5$ & $\mathbf{L}(0.24)$ & $\mathbf{L}(0.11)$ \\
\hline
\end{tabular}

\begin{tabular}{|c|c|c|}
\hline \multirow{2}{*}{$\boldsymbol{B} / \mathrm{T}$} & \multicolumn{2}{|c|}{ Rotation } \\
\cline { 2 - 3 } & CW $0.5 \mathrm{~Hz}$ & $\mathrm{ACW} 0.5 \mathrm{~Hz}$ \\
\hline$(+) 5$ & $\mathbf{L}(0.015)$ & $\mathbf{L}(0.17)$ \\
\hline$(-) 5$ & $\mathbf{L}(0.21)$ & $\mathbf{L}(0.093)$ \\
\hline
\end{tabular}

\begin{tabular}{|c|c|c|}
\hline \multirow{2}{*}{$\boldsymbol{B} / \mathrm{T}$} & \multicolumn{2}{|c|}{ Rotation } \\
\cline { 2 - 3 } & $\mathrm{CW} 0.5 \mathrm{~Hz}$ & $\mathrm{ACW} 0.5 \mathrm{~Hz}$ \\
\hline$(+) 3$ & $\mathbf{L}(0.097)$ & $\mathbf{L}(0.078)$ \\
\hline$(-) 3$ & $\mathbf{L}(0.26)$ & $\mathbf{L}(0.45)$ \\
\hline
\end{tabular}

Figure 5. Surface chirality and the ee values in various RMED conditions.

On the contrary, type II exhibits chiral signs depending on the rotational direction, as shown in Figure 4. This represents that the rotational effect is dominant at this condition. The cell rotation causes the precession of micro-MHD vortices, and the precession motion should be asymmetric between the CW and ACW vortices (Figure 1b), leading to the unbalance between right- and left-handed dislocations. Such a chiral pattern was observed at only one condition of $\{4 \mathrm{~T}, 2 \mathrm{~Hz}\}$.

Type III exhibits the chiral patterns of $3 \mathrm{~L}+\mathrm{D}$ and $\mathrm{L}+3 \mathrm{D}$, indicating that both effects of vertical MHD flow and rotation are superimposed. When the vertical MHD flows survive in RMED processes, their effects could superimpose on the rotational effects. Such RMED conditions are most probable, and the six patterns are seen in Figure 5. More detailed patterns (3L+D or L+3D) in type III would depend on the magnetic field and the rotational frequency, but it is not easy to find a rule in the chiral patterns.

On the other hand, type IV surprisingly exhibits only L-activity in the all four conditions in each table. This suggests the chiral symmetry breaking in certain conditions of RMED.

The types of chiral patterns in Figure 5. are plotted in the map with coordinates of magnetic field versus rotational frequency, as shown in Figure 6. The largest area in the middle of map is occupied by type III, which spreads from \{low magnetic fields, low frequencies\} to \{high magnetic fields, high frequencies\}. This is the most likely consequence. When the vertical MHD flows could penetrate into the tube, both the cell rotation and the vertical MHD flow could make considerable influence on the 
micro-MHD vortices. On the other hand, type I occupies the \{low magnetic fields, high frequencies\} area. The appearance of type I indicates that the cell rotation makes no influence on the micro-MHD vortices, as a result, the surface chirality is determined by the vertical MHD flows. This result suggests that the rotational frequency is too high to make interference on the micro-MHD vortices excited in this magnetic field area.

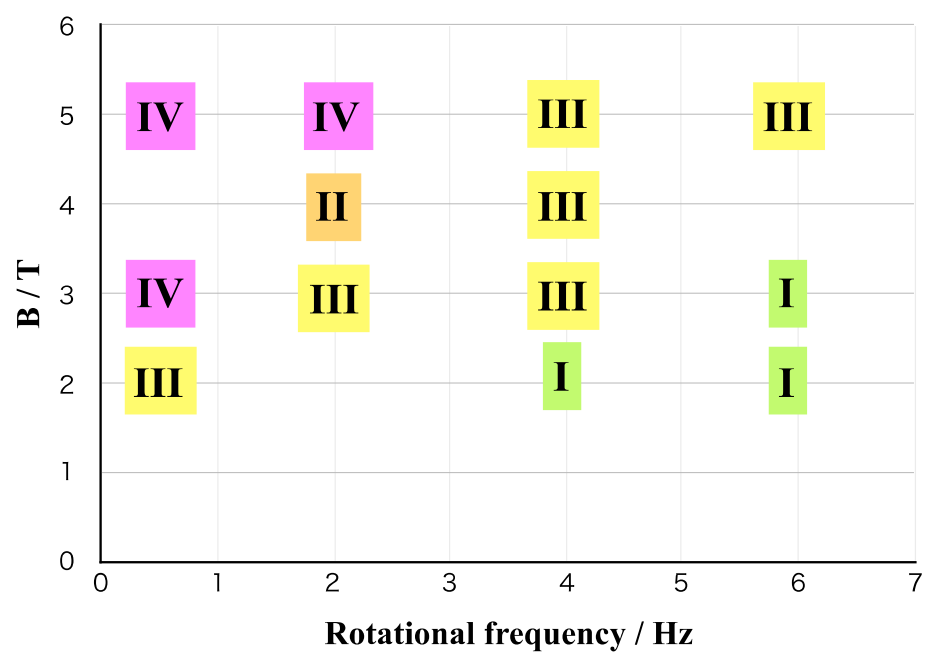

Figure 6. Mapping of four chiral types on the axes of magnetic field vs. rotational frequency.

From the above consideration, it can be expected that type II occupies the \{high magnetic fields, low frequencies $\}$ area. Actually, it is seen at $\{4 \mathrm{~T}, 2 \mathrm{~Hz}\}$. However, type IV surrounds type II and occupies most of this area. The appearance of type II indicates that the cell rotation makes strong interference on the micro-MHD vortices, as a result, it could determine the surface chirality.

Type IV exhibits only L-activity and this represents chiral symmetry breaking. A similar symmetry breaking was reported in the special conditions of MED. When the vertical MHD flow is active, the chiral sign should represent the odd dependence of magnetic field polarity, this can be written by

$$
e e(B)=-e e(-B)
$$

The breaking of such odd chirality was observed in the Cu MED with chloride additives [16,17], where the specific adsorption of chloride ions on the film surfaces causes the fluctuation in the self-organized state of micro-MHD vortices. The odd chirality breaking was also observed in the $\mathrm{Cu}$ MED at weak magnetic fields [18], where the self-organized rigid state of micro-MHD vortices cannot be well developed. These facts imply that the large fluctuation in the micro-MHD vortices causes the breaking of odd chirality.

As for type IV in RMED, if the effect of cell rotation is too strong, the precession of micro-MHD vortices could be incoherent and cause the fluctuation in the self-organized state of micro-MHD vortices. Such large fluctuation could induce the breaking of odd chirality in the RMED films for not only the magnetic field polarity but also the rotational direction. This leads to type IV.

The breaking of odd chirality was observed in several cases such as the specific adsorption of chloride ions, weak magnetic fields, and the cell rotation. The common situation is the large fluctuation of micro-MHD vortices, which includes the spacial, size, and coherence fluctuation.

As for the ee ratios in Figure 5, it should be noted that some absolute values of $e e$ ratios are larger than 0.33. This means that the peak current of an active enantiomer is two times greater than that of another one. Such large $|e e|$ ratios are surprising results in comparison with those in MED with only vertical MHD flows $(|e e|<0.1)[16]$. Thus, the RMED technique could be applicable to the synthetic methods of chiral catalysts. 


\section{Conclusions}

We have demonstrated that the surface chirality of RMED films depends on the magnetic field and the rotational frequency. There are four types of chiral behaviors: the chirality is controlled by the vertical MHD flow (type I), controlled by the cell rotational (type II), controlled by both effects (type III), and chiral symmetry breaking for both magnetic field polarity and rotational direction (type IV). The mapping of these types on the coordinates of magnetic field versus rotational frequency suggests that the strong influence of cell rotation induces the large fluctuation of micro-MHD vortices, leading to the chiral symmetry breaking. To explore higher enantioselectivity, the combination of RMED and the specific adsorption effect would be of great interest.

Author Contributions: I.M. and R.A. conceived and designed the experiments; I.M., R.M., and K.T. performed the experiments; K.T. contributed superconducting magnet tools; I.M. wrote the paper.

Funding: This research was funded by JSPS KAKENHI Grant-in-Aid for Scientific Research (C) No. 16 K04913 and 19K05230.

Acknowledgments: The authors thank the staff members of High Field Laboratory for Superconducting Materials of IMR Tohoku University for the use of the cryocooled superconducting magnet.

Conflicts of Interest: The authors declare no conflict of interest.

\section{References}

1. Switzer, J.A.; Kothari, H.M.; Polzot, P.; Nakanishi, S.; Bohannan, E.W. Enantiospecific Electrodeposition of A Chiral Catalyst. Nature 2003, 425, 490-493. [CrossRef] [PubMed]

2. Mogi, I.; Watanabe, K. Chiral Electrode Behavior of Magneto-Electrodeposited Silver Films. ISIJ Int. 2007, 47, 585-587. [CrossRef]

3. Mogi, I.; Watanabe, K. Chiral Recognition of Amino Acids by Magnetoelectrodeposited Cu Film Electrodes. Int. J. Electrochem. 2011, 239637. [CrossRef]

4. Mogi, I.; Watanabe, K. Enantioselective Recognition of Tartaric Acid on Magnetoelectrodeposited Copper Film Electrodes. Chem. Lett. 2012, 41, 1439-1441. [CrossRef]

5. Mogi, I.; Morimoto, R.; Aogaki, R. Surface Chirality Effects Induced by Magnetic Fields. Curr. Opin. Electrochem. 2018, 7, 1-6. [CrossRef]

6. Gazzotti, M.; Arnaboldi, S.; Grecchi, S.; Giovanardi, R.; Cannio, M.; Pasquali, L.; Giacomino, A.; Abollino, O.; Fontanesi, C. Spin-Dependent Electrochemistry: Enantio-Selectivity Driven by Chiral-Induced Spin Selectivity Effect. Electrochim. Acta 2018, 286, 271-278. [CrossRef]

7. Kumar, A.; Mondal, P.C.; Fontanesi, C. Chiral Magneto-Electrochemistry. Magnetoelectrochemistry 2018, 4, 36. [CrossRef]

8. Aogaki, R. Micro-MHD Effect on Electrodeposition in Vertical Magnetic Field. Magnetohydrodynamics 2003, 4, 453-460.

9. Aogaki, R.; Morimoto, R. Nonequilibrium Fluctuations in Micro-MHD Effects on Electrodeposition. In Heat and Mass Transfer: Modeling and Simulation; Hossain, M., Ed.; InTech: London, UK, 2011; pp. 189-216.

10. Yanson, Y.I.; Rost, M.J. Structural Accelerating Effect of Chloride on Copper Electrodeposition. Angew. Chem. Int. Ed. 2013, 52, 2454-2458. [CrossRef] [PubMed]

11. Sommeria, J.; Meyers, S.D.; Swinney, H.L. Laboratory Simulation of Jupiter's Great Red Spot. Nature 1988, 331, 689-693. [CrossRef]

12. Marcus, S.M. Numerical Simulation of Jupiter's Great Red Spot. Nature 1988, 331, 693-696. [CrossRef]

13. Mogi, I.; Morimoto, R.; Aogaki, R.; Takahashi, K. Effects of Vertical Magnetohydrodynamic Flows on Chiral Surface Formation in Magnetoelectrolysis. Magnetochemistry 2018, 4, 40. [CrossRef]

14. Mogi, I.; Morimoto, R.; Aogaki, R.; Watanabe, K. Surface Chirality Induced by Rotational Electrodeposition in Magnetic Fields. Sci. Rep. 2013, 3, 2574. [CrossRef] [PubMed]

15. Luo, P.; Zhang, F.; Baldwin, R.P. Constant Potential Amperometric Detection of Underivatized Amino Acids and Peptides at A Copper Electrode. Anal. Chem. 1991, 63, 1702-1707. [CrossRef]

16. Mogi, I.; Aogaki, R.; Watanabe, K. Tailoring of Surface Chirality by Micro-Vortices and Specific Adsorption in Magnetoelectrodeposition. Bull. Chem. Soc. Jpn. 2015, 88, 1479-1485. [CrossRef] 
17. Mogi, I.; Aogaki, R.; Takahashi, K. Chiral Symmetry Breaking in Magnetoelectrochemical Etching with Chloride Additives. Molecules 2018, 23, 19. [CrossRef] [PubMed]

18. Mogi, I.; Aogaki, R.; Takahashi, K. Breaking of Odd Magnetic Field Dependence of Surface Chirality in Magnetoelectrolysis. In Proceedings of the 11th PAMIR International Conference on Fundamental and Applied MHD, Reims, France, 1-5 July 2018; pp. 333-337.

(C) 2019 by the authors. Licensee MDPI, Basel, Switzerland. This article is an open access article distributed under the terms and conditions of the Creative Commons Attribution (CC BY) license (http://creativecommons.org/licenses/by/4.0/). 